\title{
The Psychometric Properties of the Self-Talk Scale among Iranian University Students
}

\author{
Mohammad Khodayarifard ${ }^{1}$, Thomas M. Brinthaupt ${ }^{2 *}$, \\ Saeed Akbari Zardkhaneh ${ }^{3}$, Golrokh Ebadi Fard Azar ${ }^{4}$ \\ ${ }^{1}$ Faculty of Psychology and Education, University of Tehran, \\ Tehran, Iran \\ ${ }^{2}$ Department of Psychology, Middle Tennessee State University, Murfreesboro, USA \\ ${ }^{3}$ Faculty of Psychology and Education, Allameh Tabatabaei University, Tehran, Iran \\ ${ }^{4}$ Faculty of Foreign Languages and Literatures, University of Tehran, \\ Tehran, Iran \\ Email: khodayar@ut.ac.ir, ”tom.brinthaupt@mtsu.edu, akbari76ir@gmail.com, gebadi@ut.ac.ir
}

Received December $16^{\text {th }}$, 2013; revised January $17^{\text {th }}, 2014$; accepted February $15^{\text {th }}, 2014$

\begin{abstract}
Copyright (c) 2014 Mohammad Khodayarifard et al. This is an open access article distributed under the Creative Commons Attribution License, which permits unrestricted use, distribution, and reproduction in any medium, provided the original work is properly cited. In accordance of the Creative Commons Attribution License all Copyrights (C) 2014 are reserved for SCIRP and the owner of the intellectual property Mohammad Khodayarifard et al. All Copyright (C) 2014 are guarded by law and by SCIRP as a guardian.
\end{abstract}

\begin{abstract}
The present study investigated the psychometric properties of the Self-Talk Scale (STS) among Iranian university students. Six hundred eight university students completed the STS and one of six self- and cognitive-related measures. The results of exploratory factor analysis showed the same four factors (i.e., self-reinforcement, self-management, self-criticism, and social-assessment) in the STS-Iranian version. Item analysis and internal consistency coefficients demonstrated that the items and factors were satisfactory. Confirmatory factor analysis also supported a four-factor model. Self-talk frequency scores were associated with personality measures in theoretically meaningful ways. The results indicate that the STS is acceptable for measuring self-talk frequency among Iranian adults.
\end{abstract}

Keywords: Self-Talk Scale (STS); Test Adaptation; Psychometric Properties; Factor Analysis; Cross-Cultural Assessment

\section{The Psychometric Properties of the Self-Talk Scale among Iranian University Students}

Many terms have been used to refer to individuals talking to themselves. These terms include internal monologues, auditory imagery, private speech, and self-talk. Among these terms, self-talk seems to be the most suitable because it is simpler and more generic than the others and can include both overt and covert conversations (Brinthaupt, Hein, \& Kramer, 2009). Selftalk is a common human experience (Fields, 2002; Vygotsky, 1934). This experience has attracted the attention of a broad range of psychologists and philosophers (e.g., Jaynes, 1976; Lyons, 1986; Mead, 1962). It is through self-talk that people interpret their feelings and perceptions, alter and regulate their assessments and beliefs, and engage in other kinds of self-regulation (Hackfort \& Schwenkmezger, 1993).

Psychological theory and research (e.g., Diaz \& Berk, 1992; Hardy, 2006) support the proposition that self-conversations serve important regulatory and cognitive functions. Researchers have investigated both the facilitating and inhibiting effects of self-talk in sports and physical activities (Hardy, 2006), clinical problems like depression and anxiety (Kendel \& Hollon, 1989; Schwartz \& Garamoni, 1889), controlling aggressive or other

\footnotetext{
*Corresponding author.
}

inappropriate behaviors and coping with fear (Meichenbaum, 1977), and improving writing skills (Breiter \& Scardamalia, 1982). How people talk to themselves is also a central concept in cognitive-behavioral interventions (Conroy \& Metzler, 2004).

In summary, theory and research highlight the importance of self-talk in everyday life. Proper assessment of self-talk is therefore a crucial aspect of psychological research in this realm. Toward this end, measures have been developed to assess various elements of self-talk (Calvete et al., 2005; Duncan \& Cheyne, 1999; Kendall \& Hollon, 1989; Siegrist, 1995). Among the available measures, the Self-Talk Scale (STS; Brinthaupt et al., 2009) seems to be the most acceptable instrument. The STS assesses several self-regulatory functions (both positive and negative) served by self-talk.

In the development and initial validation of the STS with American samples, Brinthaupt et al. (2009) identified four selftalk factors: social assessment, self-reinforcement, self-management, and self-criticism. They reported acceptable test-retest and internal consistency of the STS and evidence for its criterion and concurrent validity. Brinthaupt and Kang (in press) found good STS model-data fit that supported the proper functioning of the 5-category STS response format.

To date, there is very limited research on the external validity of the STS. In this study, we examine the psychometric proper- 
ties of the STS with Iranian students and examine how self-talk frequency relates to a variety of other self-related variables. Because of the general self-regulatory functions that are postulated to be served by self-talk, we expected that the structure and functioning of the STS would be similar to that found with American samples. These predictions are supported by a variety of studies with Iranian participants (e.g., Ghorbani, Watson, \& Hargis, 2008; Khodayarifard, Spielberger, Gholamali Lavasani, \& Akbari Zardkhaneh, 2012) that support the assumption that the adapted scales from other cultures showed similar relationships with other measures.

\section{Method}

\section{Participants}

Students from the University of Tehran were recruited through a stratified random sampling process. First, all the University colleges were divided into educational groups of human sciences, technology, engineering, basic sciences, and arts. Then, within each college, faculty members were randomly selected to include their students in the study.

The final sample consisted of 608 students (306 men, 301 women). The average age of these students was 21.92 years $(S D=2.89)$. The majority of the students were single (94.2\%), with their birth place being urban (95.7\%) rather than rural.

\section{Measures}

Self-Talk Scale (STS). The STS (Brinthaupt et al., 2009) is a 16 -item self-report measure rated on a 6-point scale $(1=$ never, $6=$ always). Each item is rated according to the common sentence stem of "I talk to myself when...” Four STS subscales measure self-talk, including social assessment (e.g., "I want to replay something I've said to another person"), self-reinforcement (e.g., "I am really happy for myself”), self-management (e.g., "I need to figure out what I should do or say"), and selfcriticism (e.g., "I am really upset with myself”). Each subscale has four items and subscales scores can range from $4-24$. Higher scores denote more frequent self-talk.

Brinthaupt et al. (2009) report internal consistency values for the subscales ranging between 0.79 and 0.89 , with a test-retest value of 0.69 over a 3 -month period. All participants completed the STS. For the current sample, internal consistency data are presented in the Results section. In addition, participants completed one of six other instruments (randomly assigned) representing a variety of self-related attributes.

Integrative Self-Knowledge Scale (ISKS). The ISKS is 12item Persian measure of the integration of experiential and reflective self-knowledge across time and the distinction of self from non-self (Ghorbani et al., 2008). Respondents rate the ISKS items using a 5-point scale $(0=$ largely untrue, $4=$ largely true). Items assess the extent to which respondents attempt to understand their past experiences, maintain awareness of self in the present, and move toward desired future goals. An example item was "What I have learned about myself in the past has helped me to respond better to difficult situations." Higher scores indicate higher levels of self-knowledge integration. Cross-cultural investigations in Iran and America (Ghorbani et al., 2008) support the reliability and validity of this measure.

Self-Esteem Scale (SES). The 10-item SES (Rosenberg,
1965) measures a person's general feelings of self-worth. This scale measures the amount of respondents' overall life satisfaction and feelings about themselves. Respondents rate each item using a 4-point scale ( 1 = strongly agree, 4 = strongly disagree). Higher scores denote higher levels of global self-esteem. The SES is a frequently used measure and has been extensively validated in the research literature (e.g., Robinson, Shaver, \& Wrightsman, 1991). For the current sample, internal consistency was acceptable, $\alpha=0.77$.

Self-Regulation Inventory, short form (SRI-S). The 25item SRI-S (Ibanez, Ruiperz, Moya, Marques, \& Ortet, 2005) measures self-regulation in five subscales: positive actions, controllability, expression of feelings and needs, assertiveness, and well-being seeking. Respondents use a 5-point rating scale ( 1 = very rarely, 5 = always $)$. Higher scores indicate higher levels of self-regulation tendencies. The psychometric properties of the SRI-S have been confirmed (e.g., Grossat-Maticek \& Eysenck, 1995; Ibanez et al., 2005). The Persian version of the SRI-S with a sample of 676 students showed Cronbach alphas for the subscales ranging from 0.90 to 0.97 and factor analysis results of the SRI confirmed the five factors (Beshārat, Bazzāziān, \& Poor Bohlul, in press; Beshārat, Bazzāziān, Azizi, Abd-al-Manāfi, \& Larijāni, in Press). For the current sample, internal consistency was acceptable, with subscale coefficients ranging from 0.87 to 0.94 .

Obsessive-Compulsive Inventory-Revised (OCI-R). The 18-item OCI-R was developed by Foa et al. (2002). This measure includes six subscales (washing, obsessing, hoarding, ordering, checking, and mental neutralizing) each of which consists of three items. Items are rated using a 5-point scale $(0=$ not at all, 4 = extremely). Higher scores indicate higher levels of OC tendencies. The alpha coefficients for these subscales have been reported in the ranges from 0.50 to 0.72 . Moreover, the 6-factor structure of the Persian version of this measure has been confirmed (Mohammadi, Zamāni, \& Fatā, 2008). For the current sample, internal consistency was acceptable, with subscale coefficients ranging from 0.49 to 0.72 .

Irrational Beliefs Test (IBT). The 100 -item IBT was developed by Jones (1968) and is a frequently used measure of irrational beliefs. It has ten subscales (e.g., demand for approval, blame proneness, anxious over-concern, and perfectionism) that are measured by ten items each. Respondents rate the items using a 5-point Likert scale (1 = strongly agree, 5 = strongly disagree). Higher scores denote lower levels of irrational beliefs. Jones (1968) reported test-retest coefficients for the total scale as 0.92 and for the subscales as ranging between 0.66 and 0.80 . In the Persian version of the measure, the internal consistency for the total scale was found to be 0.86 (Shirazi, 2006). For the current sample, internal consistency was acceptable, with subscale coefficients ranging from 0.60 to 0.71 .

Depression Anxiety Stress Scale (DASS). The DASS (Lovibond \& Lovibond, 1995) is a 42-item self-report measure of three negative emotional states. Respondents rate the items using a 4-point scale $(0=$ did not apply to me at all, $3=$ applied to me very much, or most of the time) reflecting the frequency or severity of the experiences over the past week. Higher scores denote more frequent experiences of each of the negative states. For a Persian version of the DASS, acceptable alpha coefficients have been reported, along with evidence of criterion validity (Sāhebi, Asghari, \& Salari, 2006). For the current sample, internal consistency was acceptable, with subscale coefficients ranging from 0.60 to 0.90 . 


\section{Procedure}

Prior to data collection and based of the method recommended by Tanzer and Sim (1999), the Self-Talk Scale (STS) was translated from English to Persian to be used with Iranian participants. This version was assessed for clarity by six professors in the faculty of psychology at the University of Tehran. The STS was then back-translated by three specialized English teachers. Finally, the developer of the instrument resolved any difficulties or inconsistencies. This version (see Appendix) was then used to create the final translation, which was completed by 60 B.A. and M.A. students in the University of Tehran, who rated the clarity and meaningfulness of the overall measure and individual items.

\section{Data Analysis}

Data were analyzed using the Statistical Package for Social Sciences (Version 18; SPSS Corporation, 2009) as well as the Linear Structural Relations (LISREL Version 8.5; Joreskog \& Sorbom, 1996). After the data were entered, extensive exploratory data analysis (Howell, 2007; Tukey, 1977) was conducted: 1) Approximately $5 \%$ of the completed surveys were randomly chosen and compared with the data entered in the file; 2) The observed ranges for each instrument were compared to their possible ranges; 3) We made use of demographic features of the sample group with the characteristics of the items. Because the amount of missing data, on average, was below $1 \%$ for each of the items and no orderly relation was observed, these data were replaced by using the linear interpolation method (see Marsh \& Perry, 2005); 4) We examined all participants, using a percentage bar graph to check for random response styles. Participants with any suspicious responses were deleted; 5) The 16 STS items showed approximately normal distribution. Calculating Mahalanobi's Distance (Tabachnick \& Fidel, 2007) also confirmed these results.

Following these exploratory data analysis steps, the total sample was randomly divided into two equal calibration and validation groups. The calibration sample was used for the extraction of factor structure information, by applying item analysis and exploratory factor analysis. The validation sample was used for cross-validation of the factor structure by applying confirmatory methods and checking the relations between STS scores and the other constructs pertaining to it.

\section{Results}

\section{Exploratory Factor Analysis (EFA) of the Calibration Sample Data}

Based on previous research with the STS, for the exploratory factor analysis we used the method of Principal Axial Factoring, with Direct Oblimin rotation, limiting the number of factors to four, and setting the minimal factor loading value to 0.35 . The Kaiser-Meyer-Olkin Measure of Sampling Adequacy (Kaiser, 1974) was in the acceptable range, 0.84 (Tabachnick \& Fidell, 2007).

The resulting factor analysis found four eigenvalue factors over 1.0, explaining approximately 59 percent of the variance of the total scale (see Table 1). In order to finalize the number of factors, the screen plot was used. As Table 2 shows, 14 out of the 16 STS items had suitable loading on their respective factors. Only 2 items (1 and 6) did not have the maximum loading
Table 1.

Factors and eigenvalues resulting from EFA of the STS.

\begin{tabular}{cccc}
\hline Factors & $\begin{array}{c}\text { Eigen } \\
\text { Value }\end{array}$ & $\begin{array}{c}\text { Percentage } \\
\text { of Variance }\end{array}$ & $\begin{array}{c}\text { Cumulative Percent } \\
\text { of Variance }\end{array}$ \\
\hline 1 & 5.69 & 35.54 & 35.54 \\
2 & 1.52 & 9.50 & 45.04 \\
3 & 1.15 & 7.19 & 52.23 \\
4 & 1.01 & 6.33 & 58.56 \\
\hline
\end{tabular}

on suitable theoretical factors. The data indicate that each subscale showed acceptable internal consistency coefficients.

\section{Confirmatory Factor Analysis of the Validation Sample Data}

In order to check the validity of the exploratory factor structure, we ran a confirmatory factor analysis on the validation sample, using the Maximum Likelihood method. In this process, three factor structures were tested: 1 ) the original factor structure of the scale (Brinthaupt et al., 2009); 2) the factor structure resulting from the EFA of the calibration sample data reported earlier; and 3) the original factor structure without item number 1 (because of its failure to load on any of the EFA factors).

In testing model fit, we used the following indexes: Chisquare statistic $\left(\chi^{2}\right)$, Comparative fit index (CFI; Bentler, 1990), Non-normed fit index (NNFI, Bentler, \& Bonnet, 1980), Rootmean square error of approximation (RMSEA; Stieger, 1990), Confidence interval, (CI; Hu \& Bentler, 1999), and Standard Root-Mean Square Residual (SRMR; Hu \& Bentler, 1998). Table 3 presents the results of these analyses. As the table indicates, model 3 (the original factor structure without item 1) showed the best fit.

For comparison of the relative fit of the three nested models, the $\chi_{\text {difference }}^{2}$ test was used. Comparison of model 1 and model 2 indicated that omission of item 1 and considering item 6 in Self-Management resulted in a significant improvement of fit $\left(\chi_{\text {diff }}^{2}(14)=84.10, p<0.001\right)$. Comparison of model 1 and 3 , which differed only in the omission of item 1 from the original structure, revealed significant improvement of fit, $\chi_{\text {diff }}^{2}(14)=$ 85.55, $p<0.001$. Finally, the comparison of model 2 and 3 , with displacement of item 6 from the Self-Management factor to the Social-Assessment factor, did not result in an improvement of data fit. Therefore results suggested that model 3 was the most parsimonious, since it contained the least amount of parameters while retaining the best model fit (see Table 4 descriptive statistics).

\section{Convergent and Discriminant Validity of the STS}

In order to assess the convergent validity of the STS items, we used the method of standard path coefficient (Standard Lambda, Raines-Eudy, 2000). As Table 5 shows, these coefficients indicated that the items loaded strongly on the related latent variables (factors). All of the coefficients were statistically significant.

To assess discriminant validity of subscales, we used the fixed and free solution method (Bagazzi \& Yi, 1988). This method indicates whether the one-dimensional model can explain the correlations in variables observed in every pair of factors or if these factors measure each dimension separately 


\section{KHODAYARIFARD ET AL.}

Table 2.

Descriptive statistics for the EFA of the calibration sample.

\begin{tabular}{|c|c|c|c|c|c|c|}
\hline Factor & Item \# & Mean & SD & $\begin{array}{l}\text { Cronbach's Alpha if } \\
\text { Item Deleted }\end{array}$ & $\begin{array}{c}\text { Alpha } \\
\text { Coefficient }\end{array}$ & $\begin{array}{c}\text { Corrected Item-Total } \\
\text { Correlation }\end{array}$ \\
\hline \multirow{4}{*}{ Self-Reinforcement } & 5 & 3.67 & 1.38 & 0.65 & \multirow{4}{*}{0.75} & 0.62 \\
\hline & 8 & 3.78 & 1.38 & 0.66 & & 0.60 \\
\hline & 13 & 3.73 & 1.42 & 0.71 & & 0.51 \\
\hline & 2 & 4.08 & 1.36 & 0.74 & & 0.45 \\
\hline \multirow{5}{*}{ Self-Management } & 15 & 4.10 & 1.36 & 0.64 & \multirow{5}{*}{0.73} & 0.58 \\
\hline & 3 & 4.45 & 1.37 & 0.69 & & 0.45 \\
\hline & 9 & 4.46 & 1.35 & 0.69 & & 0.44 \\
\hline & 12 & 4.18 & 1.31 & 0.68 & & 0.49 \\
\hline & 6 & 3.97 & 1.49 & 0.69 & & 0.23 \\
\hline \multirow{3}{*}{ Self-Criticism } & 7 & 4.02 & 1.42 & 0.62 & \multirow{3}{*}{0.72} & 0.56 \\
\hline & 10 & 4.25 & 1.42 & 0.64 & & 0.54 \\
\hline & 14 & 3.92 & 1.50 & 0.65 & & 0.56 \\
\hline \multirow{3}{*}{ Social-Assessment } & 11 & 4.23 & 1.36 & 0.54 & \multirow{3}{*}{0.67} & 0.51 \\
\hline & 16 & 4.11 & 1.48 & 0.65 & & 0.43 \\
\hline & 4 & 3.84 & 1.44 & 0.54 & & 0.50 \\
\hline
\end{tabular}

Table 3.

Fitness statistics for 3 models of self-talk.

\begin{tabular}{ccccccccc}
\hline Model & $\chi^{2}$ & df & CFI & NNFI & RMSEA & RMSEA (90\% CI) & SRMR \\
\hline 1 & 318.59 & 98 & 0.91 & 0.90 & 0.093 & $(0.08,0.10)$ & 0.07 \\
2 & 234.43 & 84 & 0.93 & 0.92 & 0.083 & $(0.07,0.10)$ & 0.06 \\
3 & 233.04 & 84 & 0.94 & 0.93 & 0.080 & $(0.07,0.10)$ & 0.04 \\
\hline
\end{tabular}

Table 4.

Descriptive statistics for the CFA of the validation sample.

\begin{tabular}{|c|c|c|c|c|c|c|}
\hline Factor & Item & Mean & SD & $\begin{array}{l}\text { Cronbach's Alpha if } \\
\text { Item Deleted }\end{array}$ & $\begin{array}{c}\text { Alpha } \\
\text { Coefficient }\end{array}$ & $\begin{array}{l}\text { Corrected Item-Total } \\
\text { Correlation }\end{array}$ \\
\hline \multirow{4}{*}{ Self-Reinforcement } & 2 & 3.96 & 1.42 & 0.76 & \multirow{4}{*}{0.77} & 0.50 \\
\hline & 5 & 3.75 & 1.41 & 0.72 & & 0.57 \\
\hline & 8 & 3.71 & 1.46 & 0.69 & & 0.62 \\
\hline & 13 & 3.63 & 1.46 & 0.70 & & 0.61 \\
\hline \multirow{4}{*}{ Self-Management } & 3 & 4.26 & 1.36 & 0.60 & \multirow{4}{*}{0.65} & 0.41 \\
\hline & 9 & 4.40 & 1.34 & 0.67 & & 0.30 \\
\hline & 12 & 4.17 & 1.40 & 0.52 & & 0.52 \\
\hline & 15 & 4.15 & 1.29 & 0.54 & & 0.50 \\
\hline \multirow{3}{*}{ Self-Criticism } & 7 & 3.99 & 1.41 & 0.65 & \multirow{3}{*}{0.69} & 0.45 \\
\hline & 10 & 4.18 & 1.51 & 0.52 & & 0.56 \\
\hline & 14 & 3.82 & 1.51 & 0.59 & & 0.50 \\
\hline \multirow{4}{*}{ Social-Assessment } & 4 & 3.84 & 1.52 & 0.38 & \multirow{4}{*}{0.58} & 0.38 \\
\hline & 6 & 4.02 & 1.37 & 0.39 & & 0.39 \\
\hline & 11 & 4.32 & 2.99 & 0.57 & & 0.28 \\
\hline & 16 & 4.17 & 1.50 & 0.44 & & 0.30 \\
\hline
\end{tabular}

Table 5.

Standard path and error coefficients and t-statistic for STS items.

\begin{tabular}{|c|c|c|c|c|}
\hline Factor & Item & Standard Path Coefficient & Standard Error Coefficient & t Statistic \\
\hline \multirow{4}{*}{ Self-Reinforcement } & 2 & 0.77 & 0.09 & 8.35 \\
\hline & 5 & 0.86 & 0.09 & 9.15 \\
\hline & 8 & 1 & - & - \\
\hline & 13 & 0.97 & 0.09 & 10.32 \\
\hline \multirow{4}{*}{ Self-Management } & 3 & 0.79 & 0.11 & 7.42 \\
\hline & 9 & 0.63 & 0.11 & 5.95 \\
\hline & 12 & 1 & - & - \\
\hline & 15 & 0.96 & 0.11 & 8.95 \\
\hline \multirow{3}{*}{ Self-criticism } & 7 & 0.83 & 0.11 & 7.53 \\
\hline & 10 & 1 & - & - \\
\hline & 14 & 1.02 & 0.12 & 8.63 \\
\hline \multirow{4}{*}{ Social-Assessment } & 4 & 0.92 & 0.10 & 9.15 \\
\hline & 6 & 0.61 & 0.10 & 7.18 \\
\hline & 11 & 1 & - & - \\
\hline & 16 & 0.74 & 0.10 & 4.48 \\
\hline
\end{tabular}


(Torkzādeh, Koufteros, \& Pflughoeft, 2003). We compared the fit indices for two models: the four factorial (dimensional) model (model 3 in Table 3) and the one factorial model that consisted of 15 STS items (without item 1). Table 6 shows that the Free Model has better fit statistics. This supports the notion that the STS has a multi-factorial structure.

\section{Relations of the STS Factors to Self-Related Constructs}

After demonstrating that the Persian version of the STS possessed acceptable psychometric properties, we next examined how the 4 STS factors related to a variety of self-related constructs. Table 7 shows that integrated self-knowledge was significantly and positively correlated with the STS factors of self-criticism, self-management, and social-assessment as well as with and the STS total score. Self-esteem was significantly and positively correlated with the self-management factor only. Self-regulation was significantly and positively correlated with self-reinforcement and the total STS score.

\section{Relations of the STS Factors to Cognitive Constructs}

We also examined how the STS factors correlated with cognitive constructs. As the Table 8 shows, obsessive-compulsive tendencies were significantly and positively correlated with each of the STS factors except self-management, as well as with total STS scores. Irrational beliefs scores were significantly and positively associated with self-reinforcement and total self-talk frequency scores. Depression scores were negatively correlated with self-reinforcing self-talk and positively correlated with social-assessing self-talk. Anxiety scores were positively correlated with self-critical, social-assessing, and overall self-talk frequency. Finally, stress scores were negatively correlated with self-managing self-talk.

\section{Discussion}

The principal purpose of the present research was to investigate the psychometric properties of the Self-Talk Scale (Brinthaupt et al., 2009) using an Iranian sample. The results provide strong support for the validity and cross-cultural generalization of the STS. In particular, the psychometric data show that the Persian STS adequately replicated the original scale's factor structure. Additionally, the data correlating self-talk frequency with a variety of self- and cognitive-related constructs confirm that the STS is related to these measures in theoretically meaningful ways.

In the confirmatory analysis process, the strongest support emerged for the original factor structure without one scale item. The results indicated that a self-critical self-talk item ("I should have done something differently") was problematic in the translated STS. This item showed several cross loadings in the exploratory factor analysis and the calculation of Cronbach's alpha improved when it was deleted. Further research is needed to this.

The correlational data provided convergent and discriminant validity evidence for the Persian STS. First, the results showed that the STS factors of self-criticism, self-management, and social-assessment as well as total self-talk frequency scores were significantly related to integrative self-knowledge. This construct represents a temporally integrated understanding of both experiential and reflective self-relevant processes (Ghorbani et al., 2008). The results are consistent with other research

Table 6.

Statistics of goodness of fit indices for the estimated free and fixed models.

\begin{tabular}{cccccccccc}
\hline Model & $\chi^{2}$ & df & NC & CFI & NNFI & RMSEA & RMSEA (90\% CI) & SRMR \\
\hline Free & 233.04 & 84 & 216.78 & 0.94 & 0.93 & 0.08 & $(0.07,0.10)$ & 0.04 \\
Fixed & 444.34 & 95 & 359.59 & 0.85 & 0.82 & 0.11 & $(0.10,0.12)$ & 0.16 \\
\hline
\end{tabular}

Table 7.

Correlation matrix of the STS factors with integrated self-knowledge, self-esteem, and self-management.

\begin{tabular}{ccccccc}
\hline Scale & $N$ & Self-Criticism & Self-Reinforcement & Self-Management & Social-Assessment & STS Total \\
\hline Integrated self-Knowledge & 85 & $0.32^{*}$ & 0.12 & $0.21^{*}$ & $0.44^{* *}$ & $0.51^{* *}$ \\
Self-Esteem & 78 & -0.20 & 0.20 & $0.23^{*}$ & 0.09 & -0.09 \\
Self-Regulation & 83 & -0.17 & $0.32^{*}$ & 0.14 & 0.09 & $0.79^{* *}$ \\
\hline
\end{tabular}

${ }^{*} p<0.05 ;{ }^{* *} p<0.01$.

Table 8.

Correlation matrix of the STS factors with obsessive-compulsive, irrational beliefs, and depression/anxiety/stress measures.

\begin{tabular}{ccccccc}
\hline Scale & $N$ & Self-Criticism & Self-Reinforcement & Self-Management & Social-Assessment & STS Total \\
\hline Obsessive-Compulsive & 88 & $0.34^{*}$ & $0.32^{*}$ & 0.03 & $0.33^{*}$ & $0.33^{*}$ \\
Irrational Beliefs & 82 & 0.17 & $0.36^{*}$ & 0.10 & 0.17 & $0.24^{*}$ \\
Depression & 90 & 0.09 & $-0.22^{*}$ & 0.14 & $0.24^{*}$ & 0.01 \\
Anxiety & 90 & $0.31^{*}$ & 0.21 & -0.14 & $0.23^{*}$ & $0.24^{*}$ \\
Stress & 90 & -0.14 & -0.17 & $-0.24^{*}$ & -0.13 & -0.19 \\
\hline
\end{tabular}

${ }^{*} p<0.05$. 
suggesting that self-talk serves a function in facilitating the integration of self-knowledge (e.g., Morin, 2005). Future research investigating the relationship between self-talk and integrative self-knowledge appears to be warranted.

Overall STS scores were strongly correlated with self-regulation scores. The SRI-S serves as a general assessment of people's tendencies to be autonomous and independent in regulating their lives and health (Grossarth-Maticek \& Eysenck, 1995). The results suggest that self-talk might serve an important causal or supportive role in self-regulation, or it may simply be a reflection of people's self-regulatory tendencies (e.g., Anderson, 1997).

The results comparing self-talk frequency to the cognitive measures were also of theoretical and practical interest. Obsessive-compulsive tendencies were positively associated with self-talk frequency. This finding complements the Brinthaupt et al. (2009) study that showed that frequent self-talkers reported higher levels of obsessive-compulsive propensities than did infrequent self-talkers. Consistent with other research (e.g., Schwartz \& Garamoni, 1989), depression scores were negatively correlated with self-reinforcing self-talk. Depression scores were also positively correlated with social-assessing self-talk, suggesting that ruminating about one's social interactions is related to being in a depressed state (e.g., Watkins \& Baracaia, 2002).

Higher levels of anxiety were associated with higher levels of self-critical, social-assessing, and overall levels of self-talk frequency. These results are consistent with other research showing that anxiety manifests itself in self-talk in competitive sport contexts (Conroy \& Metzler, 2004) and that specific kinds of self-talk are associated with anxiety disorders and emotional distress (e.g., Ingram, Kendall, Smith, Donnell, \& Ronan, 1987; Kendall \& Hollon, 1989).

In summary, the effective measurement of self-talk frequency permits researchers to study a variety of self-regulatory activities. The present research provides additional support for the validity of the Self-Talk Scale. The Persian translation of the STS shows good psychometric properties and can be used with confidence in future research.

\section{Acknowledgements}

This research was supported by the University of Tehran, research design No. 2/1001. The authors would like to thank Dr. Saeid Pournaghash Tehrani, Ali Azimi, and Valiollah Ramezani for back translation and control translation; Ms. Shirin Zeanali for her help with editing the paper; and Dr. Minsoo Kang for his feedback on an earlier version of the paper.

\section{REFERENCES}

Anderson, A. (1997). Learning strategies in physical education: Selftalk, imagery, and goal-setting. Journal of Physical Education Recreation \& Dance, 68, 30-35. http://dx.doi.org/10.1080/07303084.1997.10604874

Bentler, P. M. (1990). Comparative fit indexes in structural models. Psychological Bulletin, 107, 238-246.

http://dx.doi.org/10.1037/0033-2909.107.2.238

Bentler, P. M., \& Bonett, D. G. (1980). Significance tests and goodness-of-fit in the analysis of covariance structures. Psychological Bulletin, 88, 588-606. http://dx.doi.org/10.1037/0033-2909.88.3.588

Beshārat, M. A., Bazzāziān, S., \& Poor Bohlul, S. (in Press). The psychometric properties of self-regulation in Iranian Sample. Journal of Cognitive Science.

Beshart, M. A. (2010). Psychometric properties of self-regulation scale- short form in an Iranian sample. Clinical Psychology and Counseling Researches, 1, 53-70.

Brinthaupt, T. M., \& Kang, M. (in Press). Many-faceted Rasch calibration: An example using the self-talk scale. Assessment.

Brinthaupt, T. M., Hein, M. B., \& Kramer, T. E. (2009). The self talk scale: Development, factor analysis and validation. Journal of Personality Assessment, 91, 82-92.

http://dx.doi.org/10.1080/00223890802484498

Calvete, E., Estevez, A., Landin, C., Martinez, Y., Cardenoso, O., Villardon, L., \& Villa, A. (2005). Self-talk and affective problems in college students: Valence of thinking and cognitive content specificity. Spanish Journal of Psychology, 8, 56-67.

Conroy, D. E., \& Metzler, J. N. (2004). Patterns of self-talk associated with different forms of competitive anxiety. Journal of Sport and Exercise Psychology, 26, 69-89.

Duncan, R. M., \& Cheyne, J. A. (1999). Incidence and functions of self-report private speech in young adults: A self-verbalization questionnaire. Canadian Journal of Behavioral Science, 31, 133-136. http://dx.doi.org/10.1037/h0087081

Fields, C. (2002). Why do we talk to ourselves? Journal of Experimental and Theoretical Artificial Intelligence, 14, 255-272. http://dx.doi.org/10.1080/09528130110112303

Foa, E. B., Huppert, J. D., Leiberg, S., Langner, R., Kichic, R., Hajcak, G., \& Salkovskis, P. M. (2002). The obsessive-compulsive inventory: Development and validation of a short version. Psychological Assessment, 14, 485-496. http://dx.doi.org/10.1037/1040-3590.14.4.485

Ghorbani, N., Watson, P. J., \& Hargis, M. B. (2008). Integrative selfknowledge: Correlations and incremental validity of a cross-cultural scale developed in Iran and the United States. Journal of Psycholology, 142, 395-412. http://dx.doi.org/10.3200/JRPL.142.4.395-412

Grossarth-Maticek, R., \& Eysenck, H. J. (1995). Self-regulation and mortality from cancer, coronary heart disease, and other causes: A prospective study. Personality and Individual Differences, 19, 781795. http://dx.doi.org/10.1016/S0191-8869(95)00123-9

Hackfort, D., \& Schwenkmezger, P. (1993). Anxiety. In R. N. Singer, M. Murphey, \& L. K. Tennant (Eds.), Handbook of research on sport psychology (pp. 328-364). New York: Macmillan.

Howell, D. C. (2007). Statistical methods for psychology (6th ed.). Belmont, California: Duxbury Press.

Hu, L., \& Bentler, P. M. (1998). Fit indices in covariance structure modeling: Sensitivity to under parameterized model misspecification. Psychological Methods, 3, 424-453. http://dx.doi.org/10.1037/1082-989X.3.4.424

Hu, L., \& Bentler, P. M. (1999). Cutoff criteria for fit indexes in covariance structure analysis: Conventional criteria versus new alternatives. Structural Equation Modeling, 6, 1-55. http://dx.doi.org/10.1080/10705519909540118

Ibanez, M. I., Ruiperez, M. A., Moya, J., Marques, M. J., \& Ortet, G. (2005). A short version of the self-regulation inventory (SRI-S). Personality and Individual Differences, 39, 1055-1059. http://dx.doi.org/10.1016/j.paid.2005.02.029

Ingram, R. E., Kendall, P. C., Smith, T. W., Donnell, C., \& Ronan, K. (1987). Cognitive specificity in emotional distress. Journal of Personality and Social Psychology, 53, 734-742. http://dx.doi.org/10.1037/0022-3514.53.4.734

Jones, R. G. (1968). A factorial measure of Ellis' irrational belief system, with personality and maladjustment correlates. Dissertation Abstracts International, 29, 4379B-4380B.

Joreskog, K. G., \& Sorbom, D. (1996). LISREL 8: Users reference guide. Chicago: Scientific Software International.

Kaiser, H. F. (1974). An index of factorial simplicity. Psvchometrika, 39, 1-36.

Kendall, P. C., \& Hollon, S. D. (1989). Anxious self-talk: Development of the anxious self-statement questionnaire (ASSQ). Cognitive Therapy and Research, 13, 81-93. http://dx.doi.org/10.1007/BF01178491

Khodayarifard, M., Spielberger, C. D., Gholamali Lavasani, M., \& Akbari Zardkhaneh, S. (2012). Psychometric properties of farsi version of the Spielberger's state-trait anger expression inventory-2 (FSTAXI-2). Procedia-Social and Behavioral Sciences, 82, 325-329.

Lovibond, S. H., \& Lovibond, P. F. (1995). Manual for the depression anxiety stress scales (2nd ed.). Sydney: Psychology Foundation. 
Lyons, W. (1986). The disappearance of introspection. Cambridge, MA: MIT Press.

Marsh, H. W., \& Perry, C. (2005). Does a positive self-concept contribute to winning gold medals in elite swimming? The causal ordering of elite athlete self-concept and championship performances. Journal of Sport and Exercise Psychology, 27, 71-91.

Meichenbaum, D. H. (1977). Cognitive behavior modification: An integrative approach. New York: Plenum. http://dx.doi.org/10.1007/978-1-4757-9739-8

Mohammadi, A., Zamāni, R., \& Fatā, L. (2008). Validation of a Persian version of the obsessive-compulsive inventory-revised in a student sample. Psychological Research, 21, 66-77.

Morin, A. (2005). Possible links between self-awareness and inner speech: Theoretical background, underlying mechanisms, and empirical evidence. Journal of Consciousness Studies, 12, 115-134.

Raines-Eudy, R. (2000). Using structural equation modeling to test for differential reliability and validity: An empirical demonstration. Structural Equation Modeling, 7, 124-141. http://dx.doi.org/10.1207/S15328007SEM0701 07

Robinson, J. P., Shaver, P. R., \& Wrightsman, L. S. (1991). Measures of personality and social psychological attitudes. San Diego: Academic Press.

Rosenberg, M. (1965). Society and the adolescent self-image. Princeton, NJ: Princeton University Press.

Sāhebi, A., Asghari, M., \& Salari, R. (2006). Validation of depression anxiety stress scale in Iranian population. Iranian Psychology, 4, 299-312.

Schwartz, R. M., \& Garamoni, G. L. (1989). Cognitive balance and psychopathology: Evaluation of an information processing model of positive and negative states of mind. Clinical Psychology Review, 9, 271-294. http://dx.doi.org/10.1016/0272-7358(89)90058-5

Shirazi, S. (2006). The role of self-concept in relationship between depression and irrational thought among students. Masters Thesis, Tehran: Department of Psychology, Shahid Beheshti University.

Siegrist, M. (1995). Inner speech as a cognitive process mediating selfconsciousness and inhibiting self-deception. Psychological Reports, 76, 259-265. http://dx.doi.org/10.2466/pr0.1995.76.1.259

SPSS Inc. (2009). SPSS statistical algorithms. Chicago: SPSS Inc.

Tabachnick, B. G., \& Fidell, L. S. (2007). Using multivariate statistics (4th ed.). Boston, MA: Allyn and Bacon.

Tanzer, N. K., \& Sim, C. Q. E. (1999). Adapting instruments for use in multiple languages and cultures: A review of the ITC guidelines for test adaptations. European Journal of Psychological Assessment, 15, 258-269. http://dx.doi.org/10.1027//1015-5759.15.3.258

Torkzādeh, G., Koufteros, X., \& Pflughoeft, K. (2003). Confirmatory analysis of a computer self-efficacy instrument. Structural Equation Modeling, 10, 263-275. http://dx.doi.org/10.1207/S15328007SEM1002 6

Tukey, J. W. (1977). Exploratory data analysis. Reading, MA: AddisonWesley.

Vygotsky, L. S. (1934). Thinking and language. Translated by Behruz Azabdaftari (1998). Tehran: Nima Publication.

Watkins, E., \& Baracaia, S. (2002). Rumination and social problem solving in depression. Behaviour Research and Therapy, 40, 1179-1189. http://dx.doi.org/10.1016/S0005-7967(01)00098-5 


\section{Appendix}

Iranian Version of the Self-Talk Scale

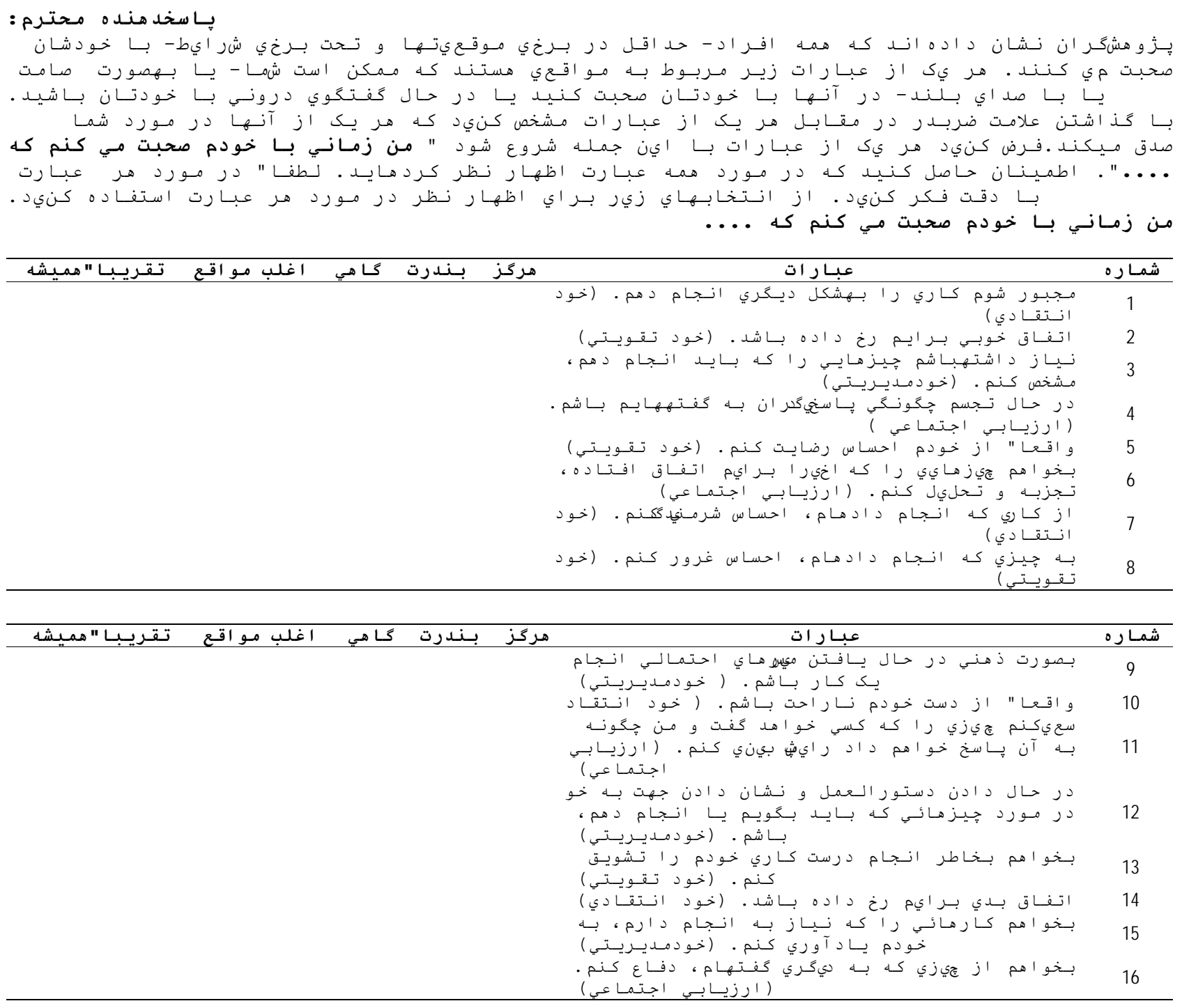

